Space-time modeling of electricity spot prices

\author{
Girum D. Abate and Niels Haldrup
}

CREATES Research Paper 2015-22 


\title{
Space-time modeling of electricity spot prices*
}

\author{
Girum D. Abate ${ }^{\dagger}$ Niels Haldrup ${ }^{\dagger}$
}

May 7, 2015

\begin{abstract}
In this paper we derive a space-time model for electricity spot prices. A general spatial Durbin model that incorporates the temporal as well as spatial lags of spot prices is presented. Joint modeling of space-time effects is necessarily important when prices and loads are determined in a network of power exchange areas. We use data from the Nord Pool electricity power exchange area bidding markets. Different spatial weight matrices are considered to capture the structure of the spatial dependence process across different bidding markets and statistical tests show significant spatial dependence in the spot price dynamics. Estimation of the spatial Durbin model show that the spatial lag variable is as important as the temporal lag variable in describing the spot price dynamics. We use the partial derivatives impact approach to decompose the price impacts into direct and indirect effects and we show that price effects transmit to neighboring markets and decline with distance. In order to examine the evolution of the spatial correlation over time, a time varying parameters spot price spatial Durbin model is estimated using recursive estimation. It is found that the spatial correlation within the Nord Pool grid has been increasing over time which we interpret as evidence for an increasing degree of market integration.
\end{abstract}

JEL classification: C32; C33

Keywords: Autoregressive; Spatial-Time series; Spatial dependence

\section{Introduction}

Whilst there is much research on the temporal dynamics of electricity spot prices (see e.g., Efimova and Serletis 2014; Haldrup et al. 2010; Haldrup and Nielsen 2006; Park et al. 2006 and Huisman and Mahieu 2003), less attention has been paid to the role of spatial dynamics of electricity spot prices. However, such dynamics are necessarily important when prices and loads are determined in a network grid of power exchange.

A number of previous studies recognize the importance of spot price interdependencies in a grid of electricity areas. Park et al. (2006), for example, point out how US regional spot market prices are characterized by spatial price interdependence. In particular, for highly interconnected transmission systems, temporal demand and supply imbalances and

\footnotetext{
*The authors acknowledge financial support from Center for Research in Econometric Analysis of Time Series-CREATES (DNRF78), funded by the Danish National Research Foundation.

†Aarhus University, Department of Economics and Business and CREATES. Fuglesangs Allé 4, 8210 Aarhus V, Denmark. Corresponding author, Niels Haldrup, e-mail: nhaldrup@econ.au.dk.
} 
possible transmission congestion may result in spatial price dependence across markets. Measurement problems in spot prices may also result in spot price spatial dependence. In deregulated electricity markets, price competition among the different markets will result in high spatial price dependence. This implies that a spot price observed in a particular market is determined (in part at least) by what happens elsewhere in the system. When forecasting spot prices in a given market, it is thus helpful to know if past and current spot prices in other markets can improve forecasts. Joint modeling of space-time effects can help investigating the dynamics of spot prices in integrated physically connected markets. Accordingly, a simultaneous space-time model of electricity prices is called for.

In time series models, temporally lagged values of the dependent variable are often included to describe the price dynamics. A similar motivation can be used to account for spatially lagged variables in electricity spot price dynamics. In deregulated electricity price markets, for example, when congestion transmission problems exist, power flows from the low price area towards the high price area. This indicates that the spot price of a particular area depends on the nearby market bidding area prices as well implying the need to account for spatial interaction effects. ${ }^{1}$

Despite the key importance of the spatial element in electricity price dynamics, spatial econometric modeling of electricity prices is rare in the literature. An exception is Douglas and Popova (2011) who estimate a spatial error model for twelve US spot market regions and show that spatial patterns play a significant role in electricity price dynamics. Congestion problems in the transmission system together with grid networks provide the framework for spatial patterns of price dynamics. One of the problems in Douglas and Popova (2011) is that they consider spatial interactions among the error terms, but not spatial interaction effects among the dependent variable and the independent variables in their model. The spatial econometrics literature stresses that ignoring spatial dependence in the dependent variable and/or in the independent variables result in biased and inconsistent coefficient estimates for the remaining variables (see e.g., LeSage and Pace 2009 and Elhorst and Yesilyurt 2014). This is a standard result in econometrics namely that if one or more relevant explanatory variables are omitted from a regression equation, then, in general the estimator of the coefficients for the remaining variables is biased and inconsistent. In contrast, ignoring spatial dependence in the error terms, if present, will only cause a loss of efficiency. Anselin (1988) also notes that when the focus of interest is to examine the existence and strength of spatial interactions, a model that includes the spatial lag of the dependent variable is more appropriate than a spatial error model. Elhorst (2010) and LeSage and Pace (2009) also recommend a spatial Durbin model (SDM) that incorporates the spatial lags of both dependent and independent variables.

The purpose of this paper is to develop a space-time model of electricity spot prices. In contrast to Douglas and Popova (2011), we derive and estimate a more flexible SDM that encompasses spatial dependence both in the dependent and independent variables of spot prices. Because the SDM nests the spatial error model as a special case, error dependence is also accounted for in the variance-covariance matrix. One of the key features of the SDM is that it produces unbiased coefficient estimates, also if the true data generating process is a spatial lag or spatial error model (see e.g., Elhorst 2010; LeSage and Fischer 2008). This is because the SDM nests the spatial lag and spatial error models as special cases.

\footnotetext{
${ }^{1}$ Modeling spatial interaction effects in mainstream economics has got wide applications recently (see e.g., Conley and Topa 2002 for unemployment dynamics, Fernandez 2011 for stock market linkages and Ertur and Koch 2007 for growth convergence), among others.
} 
For a spatial regression model, a change in the explanatory variable of a particular unit not only affects the dependent variable of that particular unit itself (direct effect) but also the dependent variables in other units (i.e, indirect/spatial spillover effects). As a result, LeSage and Pace (2009) suggest a partial derivatives impact approach because the standard point estimates of spatial regression model specifications may lead to inconsistent coefficient estimates. We use partial derivative impacts approach and decompose the price impacts into direct and indirect effects. Another feature of the spatial Durbin model is the ability to capture such direct and indirect effects. This model does not impose prior restrictions on the magnitude of the spatial spillover effects which is usually the main focus of empirical spatial econometrics. In contrast, in the spatial error model, these spatial spillover effects are set to zero by construction which implies that this model is less appropriate in applications, see Elhorst (2012) for details.

Daily spot prices from 13 bidding areas in the Nord Pool power market are used in the empirical study. The Nord Pool power grid provides an ideal candidate for spatial econometric modeling of the electricity spot price dynamics. In our empirical section, we begin by estimating the non spatial electricity spot price model using standard ordinary least squares (OLS). In order to capture weather effects on spot price dynamics, we include temperature variables as additional controls. The coefficients of the temporal lags of the spot price and temperature variables support the theoretical predictions. Unlike Douglas and Popova (2011), we apply classic Lagrange Multiplier (LM) tests for spatial panel data designed by Anselin (1988) and robust LM tests designed by Elhorst (2010) in order to test whether spatial interaction effects need to be accounted for in electricity spot price dynamics. We consider different spatial weight matrices for the LM tests and a detailed discussion on different properties of spatial weight matrices is presented. We use different spatial weight matrices, namely a) a spatial weight matrix constructed from transmission capacity of 13 bidding areas, b) a geographical contiguity weight matrix and c) a float weight matrix. The latter weight matrix is constructed based on the observation that when the power connection capacity across exchange areas allows a free float of electricity for a given hour, then prices appear to be identical across neighbor areas. On the other hand, when the capacity is insufficient, congestion will occur and prices tend to differ, see e.g. Haldrup and Nielsen (2006) and Haldrup et al. (2010). The weight matrix is constructed by calculating the fraction of hours over the entire sample period where prices are identical and hence indicates the fraction of hours with non-congestion. When a fraction is relatively high it indicates a connection that is relatively well connected in terms of power capacity. On the other hand, a small fraction indicates that the connection is relatively often subject to congestion. The classic and robust LM tests indeed indicate a highly significant spatial dependence in spot prices under all the spatial weight matrix specifications.

A general spatial Durbin model that incorporates the temporal as well as spatial lags of spot prices and weather variables is estimated using quasi Maximum likelihood estimation. We quantify and show the role of spatially lagged dependent and independent variables in spot price dynamics. The joint space-time modeling of electricity spot prices is believed to be important for different reasons. From a spot price modeling perspective, it indicates that current and past spot prices in other markets are important variables in determining current spot prices of a particular bidding market. Thus, joint modeling of space-time effects in spot prices can help improve forecasts. Giacomini and Granger (2004), for example, show that ignoring spatial correlation, even when it is weak, leads to highly inaccurate forecasts. From an econometric modeling point of view, appropriate space-time modeling of spot 
price dynamics can help avoid omitted variable bias problems, see also Case (1991).

Finally, we recursively estimate a time varying coefficients spot price SDM and examine the evolution of spot prices over time and across bidding markets and hence can provide a time varying measure of the degree of spatial correlation. We find that the spatial price correlation within the Nord Pool grid has been steadily increasing over time which we interpret as a measure of increasing degree of market integration.

The remainder of the paper is organized as follows. Section 2 provides a brief overview of the Nord Pool power market. Section 3 presents a spatial Durbin model for spot electricity prices. Section 4 presents the data used in the empirical study along with the spatial weight matrices and the main results are presented in section 5. The final section concludes.

\section{The Nordic Power System}

The Nordic countries Denmark, Finland, Norway and Sweden have deregulated their power markets in the early 1990s and have cooperated to provide an efficient power supply, see e.g., Nord Pool (2004) and Haldrup and Nielsen (2006) for brief details. Nord Pool Spot was established as a company in 2002 as the world's first market for trading power. Today it is also the world's largest market of its kind, and provides the leading market for buying and selling power in the Nordic and Baltic regions.

The Nord Pool Spot exchange area is divided into a number of bidding areas. In 2011, the Nord Pool Spot market had four bidding areas in Sweden (SE1, SE2, SE3, SE4), two bidding areas in Denmark (DK1, DK2), five bidding areas in Norway (NO1, NO2, NO3, NO4, NO5) and Estonia (EE), Finland (FI), Lithuania (LT) and Latvia (LV) constitute one bidding area each.

The different bidding areas help efficient distribution of power within the transmission system, and ensure that area market conditions are optimally reflected in the price. If grid bottlenecks exist, bidding area prices may be different (called area prices) and if there are no grid bottlenecks across neighboring interconnectors, there will be a single price across the bidding areas. When there are constraints in transmission capacity between two bidding areas, the power will always go from the low price area to the high price area. This principle is based on the law of one price: the power flow will move towards the high price area with excessive demand. This system also secures that no market members are assigned privileges on any bottleneck which is an important feature of a deregulated liberalized market.

In terms of generating capacity, the Nord Pool power is generated from different sources. In 2012, for example, over $70 \%$ of power supply in Denmark is generated from thermal plants and approximately $29 \%$ of power supply is generated from wind turbines (see Nord Pool 2013). Over $43 \%$ of power supply in Sweden is generated from hydropower while over $65 \%$ of power supply in Finland is generated from thermal power and $95 \%$ of power supply in Norway is generated from hydropower plants.

The Nordic market participants trade power contracts for next-day physical delivery at the elspot market and trading is based on an auction trade system for each hour of the following day. Day ahead power prices, known as elspot are determined based on supply and demand for every hour the following day. The Nord pool intraday market, known as elbas, helps secure the necessary balance between supply and demand in the power market. The day-ahead and intraday prices supplement each other, with the latter market acting as a balancing market to the former. The power prices considered in the present paper are 
average daily elspot prices for regions within the power grid.

\section{Spatial modeling of spot prices}

\subsection{Spatial and temporal price dependence}

Highly interconnected transmission systems, temporal demand and supply imbalances and transmission congestion in electricity spot prices may result in spatial price dependence across markets. Park et al. (2006), for example, point out that because of limited storability and cross-grid transmission, price interdependency among neighboring markets are the typical features of electricity spot prices. Unobserved features such as production capacity and maintenance problems are also likely to result in spatial spot price dependence. This implies that a spot price observed at a particular market is determined by what happens elsewhere in the system.

Consider a spot price $p_{t}$ observed in three neighboring bidding markets, $i-1, i$ and $i+1 .^{2}$ Because of the spatial proximity/and or interconnected transmission in the bidding markets, it can be assumed that the spot price at time $t$ in market $i$ depends on the spot prices at all three markets at time $t-1$, and the spot prices at two markets at time $t$. This can be visualized as

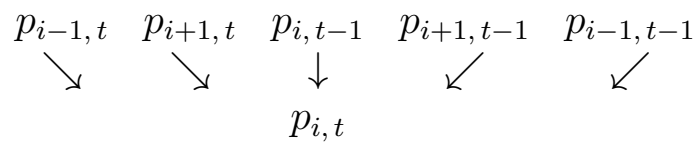

Suppose this dependence is captured by

$$
p_{i, t}=\beta p_{i, t-1}+\rho_{1} p_{i-1, t}+\rho_{2} p_{i+1, t}+\gamma_{1} p_{i-1, t-1}+\gamma_{2} p_{i+1, t-1}+c+\varepsilon_{i, t}
$$

The first term on the right hand side of equation (1) is the first temporal lag of the spot price in market $i$, the second term is the current spot price in market $i-1$, the third term is the current spot price in market $i+1$, the fourth term is the first temporal lag of spot price in market $i-1$, the fifth term is the first temporal lag of spot price in market $i+1$, $c$ is a constant and the last term is a white noise error process.

Under the assumption of no spatial price dependence among bidding markets $\left(\rho_{1}=\rho_{2}=\right.$ $\gamma_{1}=\gamma_{2}=0$ ), and equation (1) produces the conventional autoregressive $(A R(1))$ spot price process. In a highly interconnected transmission system with deregulated markets like the Nord Pool, nearby market prices still affect each other.

Using a spatial connectivity weight matrix $w_{i j}$ connecting bidding markets $i$ and $j(j=$ $i-1, i+1$ ), we can aggregate (see also Giacomini and Granger 2004) the process given in (1) as

$$
p_{i t}=\beta p_{i t-1}+\rho \sum_{j=i-1}^{i+1} w_{i j} p_{j t}+\gamma \sum_{j=i-1}^{i+1} w_{i j} p_{j t-1}+c+\varepsilon_{i t}
$$

\footnotetext{
${ }^{2}$ Note that we will use bidding markets and bidding areas interchangeably.
} 
where $\rho$ is a parameter measuring the strength of spatial (contemporaneous) dependence between bidding markets, $w_{i j}$ is a spatial weight coefficient, $\gamma$ is a coefficient measuring lagged spatial dependence and $\varepsilon_{i t}$ is a white noise process. It is clear from (2) that a spatial lag is a distributed lag, rather than a shift in a given direction like in the time series case. Here each spatial weight $w_{i j}$ to be discussed latter reflects the spatial influence of bidding market $j$ on bidding market $i$. Note that we consider temporal as well as spatial lags to be of first order for simplicity.

Equation (2) can be generalized (in matrix form) as

$$
p_{t}=\rho W p_{t}+\beta p_{t-1}+\gamma W p_{t-1}+Z_{t} \theta_{1}+W Z_{t} \theta_{2}+c+\varepsilon_{t}
$$

where $p_{t}$ is an $N x 1$ vector of spot prices during the sample period time $t, W$ is an $N x N$ spatial weight matrix connecting bidding areas $i$ and $j, \beta, \theta_{1}$ and $\theta_{2}$ are associated parameters, $Z_{t}$ is a set of control (e.g., weather conditions, time dummies etc.) variables, and $\varepsilon_{t}$ is a white noise vector process. The model given in (3) is known as the spatial Durbin model (SDM) as it includes the spatial lags of both the dependent and independent variables. In section 4.2 we will discuss the design of the weight matrix $\mathrm{W}$ in more detail.

The spot price $p_{t}$ is related to spot prices in neighboring bidding markets in the current time period $W p_{t}$, previous periods spot prices $p_{t-1}$, previous periods spot prices from neighboring bidding markets $W p_{t-1}$, a set of control variables in the current period $Z_{t}$ as well as a set of control variables from neighboring markets $W Z_{t}$ which are thought to exert influence on current spot prices.

LeSage and Pace (2009) explicitly discuss a number of theoretical econometric as well as economic motivations for incorporating spatial lag variables in a regression framework. In our particular case the model in (3) captures the possible spatial interaction effects that may arise in the system grid.

One of the distinctive features of the SDM in (3) is that it nests various models as a special case. Under the assumption of no spatial interactions, $\rho=0, \gamma=0$ and $\theta_{2}=0$, produces the conventional spot price time regression model. Imposing the restriction that $\gamma=0$ and $\theta_{2}=0$ produces the spatial autoregressive (SAR) model of the form

$$
p_{t}=\rho W p_{t}+\beta p_{t-1}+Z_{t} \theta_{1}+c+\varepsilon_{t}
$$

The SAR model contains linear combinations of the dependent variable as additional explanatory variables but excludes the spatial lags of the independent variables. This model assumes that exogenous factors (e.g., weather conditions and previous periods spot prices) observed in neighboring areas do not have direct effect on spot prices of a particular bidding market. In the standard spatial econometrics literature, the restriction $\gamma=0$ and $\theta_{2}=0$ is used to test the hypothesis whether the SDM can be reduced to the spatial lag model.

Similarly, imposing the restrictions $\gamma+\rho \beta=0$, and $\theta_{2}+\rho \theta_{1}=0$, equation (3) produces the spatial error model (SER) of the form

$$
p_{t}=\beta p_{t-1}+\theta_{1} Z_{t}+(I-\rho W)^{-1}\left(c+\varepsilon_{t}\right)
$$

These restrictions also allow to test the hypothesis whether the SDM can be reduced to the spatial error model. The SER specification implies that spatial interaction effects occur through spatial propagation of unobserved disturbances.

Consider the SER model in (4) rewritten as 


$$
p_{t}=\beta p_{t-1}+\theta_{1} Z_{t}+c^{\prime}+\mu_{t}
$$

where $c^{\prime}=(I-\rho W)^{-1} c, \quad \mu_{t}=(I-\rho W)^{-1} \varepsilon_{t}$ or $\mu_{t}=\rho W \mu_{t}+\varepsilon_{t}$. This specification shows that the scalar error process $\mu_{i t}$ in a particular bidding market $i$ at time $t$ is a weighted average of the errors in neighboring bidding markets and its own local disturbance $\varepsilon_{i t}$.

Using $(I-\rho W)^{-1}=I+\sum_{k=1}^{\infty}(\rho W)^{k}$, we can write $\mu_{t}$ as

$$
\mu_{t}=\left(I+\rho W+\rho^{2} W^{2}+\ldots\right) \varepsilon_{t}
$$

If the error vector process $\varepsilon_{t}$ is $i . i . d$, the variance-covariance matrix of the local disturbance (see e.g., Kapoor et al. 2004) is given as

$$
\begin{aligned}
E\left(\mu_{t} \mu_{t}^{\prime}\right) & =\sigma_{\varepsilon}^{2}(I-\rho W)^{-1}(I-\rho W)^{-1^{\prime}} \\
& =\sigma_{\varepsilon}^{2}\left[I+\rho\left(W+W^{\prime}\right)+\rho^{2}\left(W^{2}+W W^{\prime}+W^{\prime 2}\right)+\ldots\right]
\end{aligned}
$$

The variance-covariance matrix implies that if $|\rho|<1$, the equilibrium disturbances are correlated with each other but closer neighbors are more correlated than distant neighbors.

Douglas and Popova (2011) state that the SER model is more appropriate to model electricity prices because it is relatively convenient to estimate using panel data sets. As stated earlier, when the interest is to examine spatial interactions, a full model specification of the spatial interaction process is more appropriate than the SER model. The SDM which is more flexible than the SER model produces unbiased coefficient estimates even if the true DGP is SER. This is because the SER model is nested within the SDM, and as a result error dependence is accounted for the variance-covariance matrix. In our empirical section too, a test on parameter restrictions shows that both the SAR and SER model are rejected in favor of the SDM.

\section{Empirical results}

\subsection{Data}

Daily spot market electricity prices for 13 bidding areas during the period 1 January 2012 to 31 August 2014 (a total of 12,662 observations) from the Nord Pool power market are used. The spot market bidding areas include four regions from Sweden (SE1, SE2 SE3, SE4), one region from Finland (FI), two regions from Denmark (DK1, DK2), five regions from Norway (NO1, NO2, NO3, NO4, NO5), and one region from Estonia (EE). See figure 2 for locations of the bidding areas. Data for the bidding areas in Estonian-Latvian border, Latvia and Lithuania, is not included because complete spot price data is not available for the years 2012 and 2013. 
Figure 1: Map of the Nord Pool bidding areas: Numbers are transmission capacities

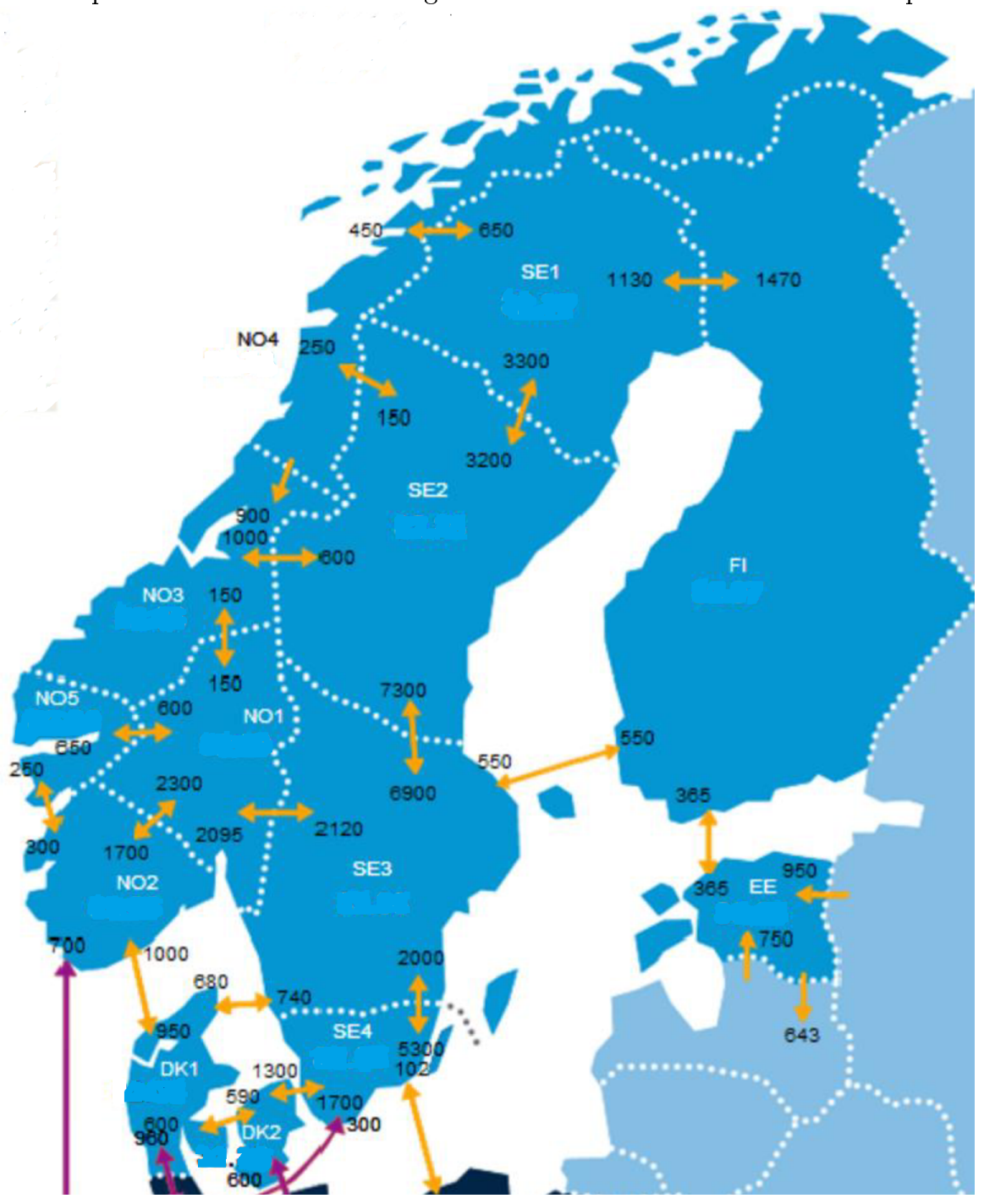

Source: Nord Pool 2014

The data series are plotted in figure 3 for each of the 13 bidding markets where it can be seen that, in general, the spot prices show huge fluctuations.

Whereas bidding areas from Sweden (SE1, SE2, SE3, SE4), Norway (NO1, NO2, NO3, NO4, NO5) and Finland (FI) tend to show similar spot price patterns, the bidding areas in Denmark (DK1 and DK2) also show a similar pattern while the spot price pattern in Estonia (EE) is rather different. 
Figure 2: Daily spot prices for 13 bidding markets in Nord Pool: 1 January 2012-31 August 2014
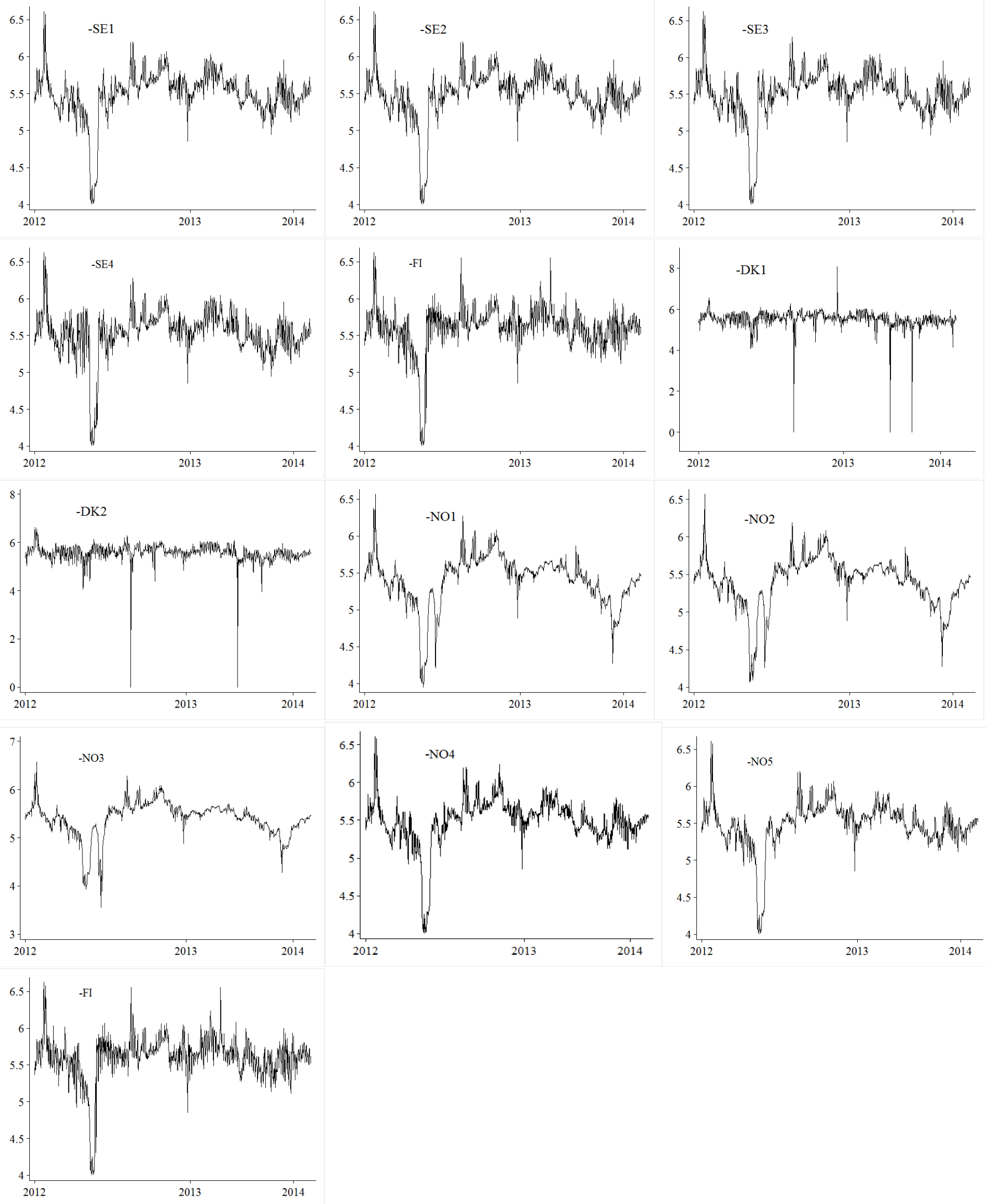
The descriptive statistics of daily spot prices for each of the 13 Nord Pool spot markets are also reported in table 1 . The mean spot price for the 13 bidding markets is more or less the same across different markets. The mean spot price ranges from its maximum 5.680 in EE to its minimum 5.397 in NO3. The daily spot prices also show similar patterns in standard deviation across different bidding areas. ${ }^{3}$ The lowest standard deviation is observed in EE while the highest standard deviation is observed in DK1. ${ }^{4}$

Average cooling degree days (CDD) and average heating degree days (HDD) ${ }^{5}$ that capture daily weather effects in electricity spot prices are calculated using approximate weather locations for each of the 13 bidding areas.

Table 1: Spot price descriptive statistics in 13 Nord Pool bidding areas

\begin{tabular}{cccccccccccccc}
\hline \hline & SE1 & SE2 & SE3 & SE4 & FI & DK1 & DK2 & NO1 & NO2 & NO3 & NO4 & NO5 & EE \\
\hline Min & 4.005 & 4.005 & 4.005 & 4.005 & 4.005 & 0 & 0 & 3.949 & 4.067 & 3.556 & 4.005 & 4.005 & 5.116 \\
Mean & 5.502 & 5.503 & 5.512 & 5.539 & 5.608 & 5.524 & 5.569 & 5.409 & 5.407 & 5.397 & 5.497 & 5.489 & 5.680 \\
Max & 6.607 & 6.607 & 6.624 & 6.624 & 6.624 & 8.087 & 6.624 & 6.568 & 6.568 & 6.568 & 6.607 & 6.607 & 6.835 \\
Std.dev & 0.315 & 0.315 & 0.321 & 0.318 & 0.306 & 0.439 & 0.375 & 0.351 & 0.331 & 0.369 & 0.311 & 0.307 & 0.196 \\
\hline
\end{tabular}

\subsection{Spatial weight matrix for spot prices}

The specification of the spatial weight matrix $W$ is a very important issue in spatial econometrics. However, typically there is little guidance in the choice of the correct spatial weight matrix in empirical applications. The usual tradition in constructing the spatial weight matrix has been geographical distance. However, it is not obvious that geography is the most relevant factor in spatial interactions between the economic units under consideration (Case et al., 1993). The weight matrix represents the influence process assumed to be present in the network and hence the choice of the weight matrix is supposed to represent the theory a researcher has about the structure of the influence of the processes in the network, see also Leenders (2002).

Figure 3: Four hypothetical neighboring electricity bidding markets

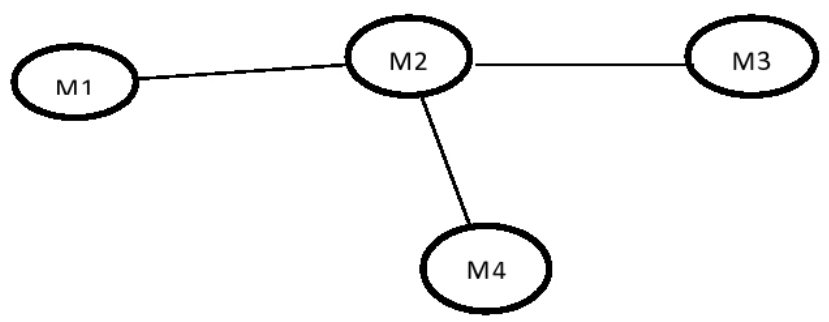

In the spatial econometric model (2), each spatial weight $w_{i j}$ reflects the spatial influence of bidding market $j$ on bidding market $i$. Consider, for example, four hypothetical neighboring bidding markets $M 1, M 2, M 3$ and $M 4$ displayed as in figure 3. Bidding market $M 1$ is neighbor

\footnotetext{
${ }^{3} \mathrm{~A}$ wide range of unit root tests were conducted and they all strongly reject the unit root hypothesis.

${ }^{4}$ We have 3 negative prices in DK1 and 2 negative prices in DK2 and treat them as missing observations when taken in $\log$ terms.

${ }^{5}$ Weather Underground (http://www.degreedays.net/) provides world wide cooling and heating degree days for many weather locations in the world. We used approximate city weather locations in the calculation of the CDD and HDD for each of the 13 bidding areas.
} 
to $M 2, M 3$ and $M 4$ (considering first and second order neighborhood) whereas bidding market $M 2$ is also first order neighbor to bidding markets $M 3$ and $M 4$. Then, a first order binary contiguity weight matrix $W$ (1 if two bidding markets are neighbors to each other and 0 otherwise) and its square $W^{2}$ can be specified as

$$
W=\left(\begin{array}{ccccc} 
& M 1 & M 2 & M 3 & M 4 \\
M 1 & 0 & 1 & 0 & 0 \\
M 2 & 1 & 0 & 1 & 1 \\
M 3 & 0 & 1 & 0 & 0 \\
M 4 & 0 & 1 & 0 & 0
\end{array}\right) \text { and } W^{2}=\left(\begin{array}{ccccc} 
& M 1 & M 2 & M 3 & M 4 \\
M 1 & 1 & 0 & 1 & 1 \\
M 2 & 0 & 3 & 0 & 0 \\
M 3 & 1 & 0 & 1 & 1 \\
M 4 & 1 & 0 & 1 & 1
\end{array}\right)
$$

The weights are assumed to be non-stochastic and exogenously given with the properties; (i) $w_{i j} \geqslant 0$, (ii) $w_{i j}=0$ if $i=j$, for any $i=1, \ldots, N$. The second property implies that no bidding markets are considered neighbors to themselves. Note that the square matrix $W^{2}$ reflects second order contiguity neighbors (that are neighbors to the first order neighbors). Because second order neighbor to a particular observation $i$ includes observation $i$ itself, $W^{2}$ has non zero diagonal elements, see LeSage and Pace (2009) for details. Sometimes the weight matrix is normalized such that $\sum_{j \neq i}^{N} w_{i j}=1$, for $i=1, \ldots, N$.

In order to capture the electrical transmission capacity of bidding areas, we follow Douglas and Popova (2011) to construct the transmission weight matrix. We construct the transmission weight matrix in table 2 using the transmission capacity available for each of the 13 Nord Pool bidding markets. The elements of the weight matrix are row normalized transmission capacities (in megawatts) available between each bidding market. If there is no transmission capacity between bidding areas, the element of the weight matrix is zero. We assume the transmission capacity available is constant over the sample period.

The transmission capacity between any two bidding areas (how much power can be transmitted in the grid) captures the possible spatial interactions between these areas. If the spot prices differ between two areas, then the transmission capacity across these areas is fully utilized towards the area with the higher price. If the capacity between two areas is not fully utilized the prices in these two areas will be equal.

Table 2: Transmission weight matrix for the 13 Nord Pool bidding areas

\begin{tabular}{cccccccccccccc}
\hline \hline & SE1 & SE2 & SE3 & SE4 & FI & DK1 & DK2 & NO1 & NO2 & NO3 & NO4 & NO5 & EE \\
\hline SE1 & 0 & 0.133 & 0 & 0 & 0.669 & 0 & 0 & 0 & 0 & 0 & 0.199 & 0 & 0 \\
SE2 & 0.325 & 0 & 0.572 & 0 & 0 & 0 & 0 & 0 & 0 & 0.079 & 0.0246 & 0 & 0 \\
SE3 & 0 & 0.504 & 0 & 0.297 & 0.083 & 0.047 & 0 & 0.069 & 0 & 0 & 0 & 0 & 0 \\
SE4 & 0 & 0 & 0.606 & 0 & 0 & 0 & 0.394 & 0 & 0 & 0 & 0 & 0 & 0 \\
FI & 0.328 & 0 & 0.362 & 0 & 0 & 0 & 0 & 0 & 0 & 0 & 0 & 0 & 0.309 \\
DK1 & 0 & 0 & 0.425 & 0 & 0 & 0 & 0 & 0 & 0.575 & 0 & 0 & 0 & 0 \\
DK2 & 0 & 0 & 0 & 1 & 0 & 0 & 0 & 0 & 0 & 0 & 0 & 0 & 0 \\
NO1 & 0 & 0 & 0.409 & 0 & 0 & 0 & 0 & 0 & 0.427 & 0.036 & 0 & 0.128 & 0 \\
NO2 & 0.194 & 0 & 0 & 0 & 0 & 0.299 & 0 & 0.478 & 0 & 0 & 0 & 0.029 & 0 \\
NO3 & 0 & 0.400 & 0 & 0 & 0 & 0 & 0 & 0 & 0 & 0 & 0.600 & 0 & 0 \\
NO4 & 0.750 & 0.250 & 0 & 0 & 0 & 0 & 0 & 0 & 0 & 0 & 0 & 0 & 0 \\
NO5 & 0 & 0 & 0 & 0 & 0 & 0 & 0 & 0.872 & 0.128 & 0 & 0 & 0 & 0 \\
EE & 0 & 0 & 0 & 0 & 1 & 0 & 0 & 0 & 0 & 0 & 0 & 0 & 0 \\
\hline
\end{tabular}

Bidding markets corresponding to columns and rows are from Sweden (SE1, SE2, SE3, SE4), from Finland (FI),

from Denmark (DK1, DK2), from Norway (NO1, NO2, NO3, NO4, NO5) and from Estonia (EE).

If there is insufficient transmission capacity between the two areas bottlenecks occur and 
price differences will naturally arise. The surplus area will have a lower price than the deficit area as more power is available compared to consumption. Consider, for example, two bidding areas with SE1 as a lower price area and SE2 a high price area. If no transmission lines were available between the two areas they would have different prices. Assume there is a capacity of $K$ megawatt (MW) available between SE1 and SE2. The price in SE2 would then move towards a lower price due to additional supply and the price in SE1 would move towards a higher price due to higher demand. The available transmission capacity is used to level out price differences as much as possible.

When the power connection capacity across exchange areas allows a free float of electricity for a given hour, then prices appear to be identical across neighbor areas. On the other hand, when the capacity is insufficient congestion will occur and prices tend to differ, see e.g., Haldrup and Nielsen (2006) and Haldrup et al. (2010). An alternative weight matrix we consider is based on this observation. It is constructed by calculating the fraction of hours over the entire sample period where prices are identical and hence indicates the fraction of hours with non-congestion. When a fraction is relatively high it indicates a connection that is relatively well connected in terms of power capacity. On the other hand, a small fraction indicates that the connection is relatively often subject to congestion. The fraction in each cell in table 3 represents the fraction of hours where prices are identical between bidding markets to the total number of hours in the sample period. SE1 and SE2, for example, have a fraction of 0.992 and hence indicates an exchange point with an almost free float and hence a high degree of spatial dependence. We will refer to the weight matrix defined in this fashion as a "float weight matrix".

Table 3: Float weight matrix

\begin{tabular}{cccccccccccccc}
\hline \hline & SE1 & SE2 & SE3 & SE4 & FI & DK1 & DK2 & NO1 & NO2 & NO3 & NO4 & NO5 & EE \\
\hline SE1 & 0 & 0.992 & 0.962 & 0.897 & 0.655 & 0.552 & 0.688 & 0.523 & 0.462 & 0.868 & 0.833 & 0.488 & 0.511 \\
SE2 & 0.992 & 0 & 0.971 & 0.904 & 0.656 & 0.530 & 0.557 & 0.530 & 0.469 & 0.859 & 0.825 & 0.495 & 0.442 \\
SE3 & 0.962 & 0.971 & 0 & 0.929 & 0.676 & 0.577 & 0.714 & 0.535 & 0.473 & 0.836 & 0.805 & 0.498 & 0.458 \\
SE4 & 0.897 & 0.904 & 0.929 & 0 & 0.629 & 0.595 & 0.759 & 0.507 & 0.448 & 0.779 & 0.750 & 0.477 & 0.435 \\
FI & 0.655 & 0.656 & 0.676 & 0.629 & 0 & 0.405 & 0.498 & 0.373 & 0.332 & 0.574 & 0.562 & 0.344 & 0.721 \\
DK1 & 0.552 & 0.530 & 0.577 & 0.595 & 0.405 & 0 & 0.789 & 0.385 & 0.395 & 0.483 & 0.467 & 0.362 & 0.276 \\
DK2 & 0.688 & 0.557 & 0.714 & 0.759 & 0.498 & 0.789 & 0 & 0.409 & 0.385 & 0.603 & 0.587 & 0.382 & 0.346 \\
NO1 & 0.523 & 0.530 & 0.535 & 0.507 & 0.373 & 0.385 & 0.409 & 0 & 0.892 & 0.492 & 0.483 & 0.897 & 0.229 \\
NO2 & 0.463 & 0.469 & 0.473 & 0.448 & 0.332 & 0.395 & 0.386 & 0.892 & 0 & 0.435 & 0.425 & 0.822 & 0.208 \\
NO3 & 0.868 & 0.859 & 0.836 & 0.778 & 0.574 & 0.483 & 0.603 & 0.492 & 0.435 & 0 & 0.935 & 0.460 & 0.379 \\
NO4 & 0.833 & 0.825 & 0.805 & 0.750 & 0.562 & 0.467 & 0.587 & 0.483 & 0.425 & 0.935 & 0 & 0.453 & 0.370 \\
NO5 & 0.488 & 0.495 & 0.498 & 0.477 & 0.344 & 0.362 & 0.382 & 0.897 & 0.822 & 0.460 & 0.452 & 0 & 0.212 \\
EE & 0.511 & 0.442 & 0.458 & 0.435 & 0.721 & 0.276 & 0.346 & 0.229 & 0.208 & 0.379 & 0.370 & 0.215 & 0 \\
\hline
\end{tabular}

Bidding markets corresponding to columns and rows are from Sweden (SE1, SE2, SE3, SE4), from Finland (FI), from Denmark (DK1, DK2), from Norway(NO1, NO2, NO3, NO4, NO5) and from Estonia (EE).

We also consider a contiguity weight matrix as an alternative specification, where the elements of the contiguity weight matrix are 1 if two bidding markets are neighbors to each other and zero otherwise.

\subsection{Quasi-maximum likelihood estimation of the SDM}

Any of the spatial econometric models we discussed in section (3) can be estimated by maximum likelihood (ML) (Anselin 1988), quasi-maximum likelihood (QML) (Lee 
2010), instrumental variables (IV) (Anselin 1988), generalized method of moments (GMM) (Kelejian and Prucha 1999), or by Bayesian Markov Chain Monte Carlo methods (Bayesian MCMC) (LeSage 1997). One advantage of QML estimators is that they do not rely on the assumption of normality of the disturbances. One disadvantage of the IV/GMM estimators is the possibility of ending up with a coefficient estimate for the spatial autoregressive coefficient outside its parameter space.

Following Lee and $\mathrm{Yu}$ (2008) we use the quasi maximum likelihood to estimate our SDM. Consider the SDM

$$
p_{t}=\rho W p_{t}+\beta p_{t-1}+\gamma W p_{t-1}+\theta_{1} Z_{t}+\theta_{2} W Z_{t}+c+\varepsilon_{t}
$$

Denote $\psi=\left(\delta^{\prime}, \rho, \sigma^{2}\right)^{\prime}$ and $\varsigma=\left(\delta^{\prime}, \rho, c^{\prime}\right)^{\prime}$ where $\delta=\left(\beta, \gamma, \theta_{1}^{\prime}, \theta_{2}^{\prime}\right)^{\prime}$. At the true value,

$\psi_{0}=\left(\delta_{0}^{\prime}, \rho_{0}, \sigma_{0}^{2}\right)^{\prime}$ and $\varsigma_{0}=\left(\delta_{0}^{\prime}, \rho_{0}, c_{0}^{\prime}\right)^{\prime}$ where $\delta_{0}=\left(\beta_{0}, \gamma_{0}, \theta_{01}, \theta_{02}^{\prime}\right)^{\prime}$. The likelihood function of (5) is (Lee 2004)

$$
\ln L(\psi, c)=-\frac{N T}{2} \ln (2 \pi)-\frac{N T}{2} \ln \left(\sigma^{2}\right)+T \ln |I-\rho W|-\frac{1}{2 \sigma^{2}} \sum_{t=1}^{T}\left[\varepsilon_{t}^{\prime}(\varsigma) \varepsilon_{t}(\varsigma)\right]^{\prime}
$$

where $\varepsilon_{t}(\varsigma)=S(\varsigma) p_{t}-\beta p_{t-1}-\gamma W p_{t-1}-Z_{t} \theta_{1}-Z_{t} W \theta_{2}-c$, and $S(\varsigma)=I-\rho W$. Thus $\varepsilon_{t}(\varsigma)=\varepsilon_{t}\left(\varsigma_{0}\right)$.

The QMLEs $\hat{\psi}$ and $\hat{c}$ are the extreme estimators derived from the maximization of equation (6). When the disturbances $\varepsilon_{t}$ are normally distributed, $\hat{\psi}$ and $\hat{c}$ are the MLEs. But when the disturbances $\varepsilon_{t}$ are not normally distributed, $\hat{\psi}$ and $\hat{c}$ are QMLEs. Lee (2010) and Lee and $\mathrm{Yu}$ (2008) show that the QMLEs have the usual asymptotic properties including (consistency, normality and efficiency) for dynamic spatial econometric models

\section{$5 \quad$ Results and testing for spatial interaction effects}

Before we estimate the SDM given in (3), we estimate the non-spatial version of equation (3) assuming $\rho=0, \gamma=0$ and $\theta_{2}=0$. Schwarz loss, Akaike loss and Hannan and Quinn's phi measures all suggest that the $4^{\text {th }}$ lag is the optimal temporal lag length. Day-of week dummies were also included as additional covariates in the model. Table 4 contains the $O L S$ estimation results of model (3) without spatial interaction effects. The coefficient of the first, second and fourth temporal lag price are positive and significant. The heating degree variable enters with a significant coefficient estimates reflecting that electricity is a significant energy source for heating in the Nordic countries.

In order to test whether spatial interaction effects need to be accounted for in electricity spot price dynamics, we apply classic Lagrange Multiplier (LM) tests for panel data designed by Anselin (1988) and robust LM tests designed by Elhorst (2010). The LM test statistics for spatial interaction effects among the dependent variable is known as the spatial lag model. The LM test among the error terms, on the other hand, is known as the spatial error model. Both the LM lag and LM error tests which are based on the residuals of the non-spatial model are asymptotically distributed as $\chi 2(1)$. These test the null hypothesis of no spatial interactions against the alternative hypothesis of spatial interactions. Anselin (1988) points out that since both tests can have power against the other alternative, it is important to take account of possible spatial lag dependence when testing for spatial error dependence and the vice versa. The robust LM test takes into 
account such misspecification of the other forms, see Anselin et al. (1996) for technical details.

Table 4: Estimation results: The non spatial model with tests for dynamics using transmission, contiguity and float weight matrices.

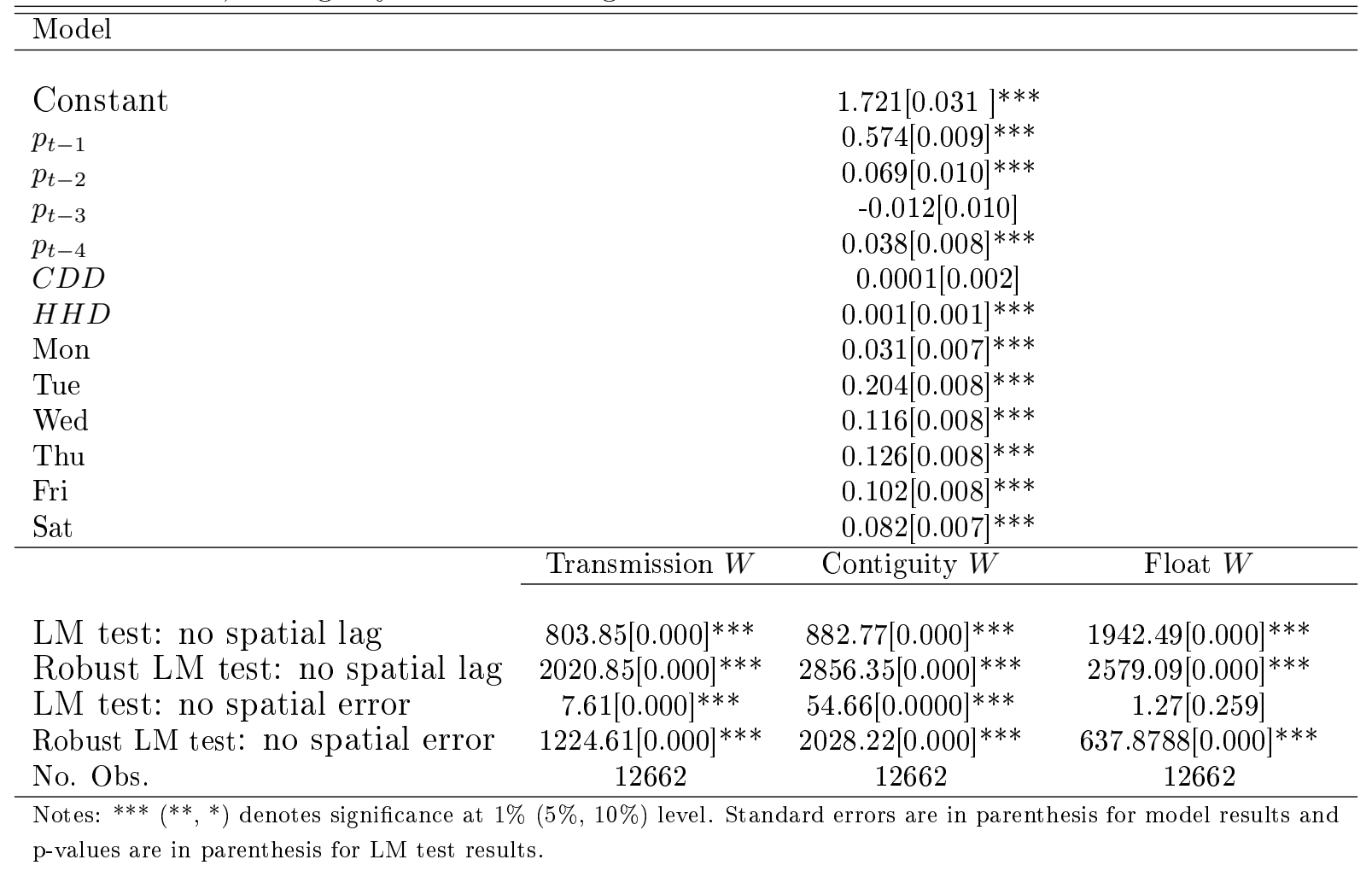

The LM test results under the different weight matrices namely the transmission, contiguity and float weight matrix are reported in the lower panel of table 4 . Note that all the different weight matrices are used in row normalized form. When using the classic LM test under the transmission weight matrix, both the hypothesis of no spatially lagged dependent variable and no spatially lagged error term must be rejected. The robust LM tests also reject both the hypothesis of no spatially lagged dependent variable and no spatially lagged error term. This indicates that the non-spatial model is rejected in favor of either the spatial lag or spatial error model implying the need to account for spatial interaction effects. ${ }^{6}$

When using the contiguity weight matrix, both the classic and the robust LM tests reject the hypothesis of both no spatially lagged dependent variable and no spatially lagged error term. The LM test results under the float weight matrix also produce more or less similar results. Elhorst and Yesilyurt (2014) and LeSage and Pace (2009) recommend that when both the classic and robust LM tests reject the non-spatial model in favor of either to the spatial lag or spatial error model, one better adopts the SDM. We, thus proceed to the estimation of the SDM.

Prior to the SDM estimation, it is of interest to examine the simple cross-correlation of spot prices in the 13 bidding areas. Table 5 contains cross-correlations of the residuals of the 13 bidding areas of the Nord Pool power market. The bidding areas show an average cross-correlation of 0.694 between each other. The residuals of bidding areas from Sweden

\footnotetext{
${ }^{6}$ Anselin (1988) illustrates that when both the classic LM lag and LM error tests give similar results, one better considers the robust LM specification tests.
} 
(SE1, SE2, SE3, SE4), Norway (NO1, NO2, NO3, NO4, NO5) and Finland (FI) show strong correlations between each other. This correlation also captures the pattern of spot prices displayed in figure 2. Residuals in bidding markets from Denmark (DK1, DK2) on the other hand, show relatively weak correlation with the above bidding markets but exhibit strong correlation between themselves. Whereas the strongest cross-correlation of residuals is observed between SE1 and SE2, the weakest cross-correlation of residuals is observed between DK1 and NO3.

Table 5: Cross-bidding market correlation (mean $=0.694)$ of spot prices

\begin{tabular}{lccccccccccccc}
\hline \hline & SE1 & SE2 & SE3 & SE4 & FI & DK1 & DK2 & NO1 & NO2 & NO3 & NO4 & NO5 & EE \\
\hline SE1 & 1 & 0.999 & 0.984 & 0.921 & 0.799 & 0.358 & 0.434 & 0.862 & 0.839 & 0.823 & 0.981 & 0.971 & 0.639 \\
SE2 & 1 & 0.985 & 0.922 & 0.799 & 0.359 & 0.435 & 0.861 & 0.839 & 0.822 & 0.979 & 0.969 & 0.638 \\
SE3 & & & 1 & 0.938 & 0.812 & 0.369 & 0.446 & 0.848 & 0.823 & 0.809 & 0.963 & 0.952 & 0.643 \\
SE4 & & & 1 & 0.769 & 0.391 & 0.484 & 0.788 & 0.765 & 0.749 & 0.899 & 0.891 & 0.601 \\
FI & & & & 1 & 0.354 & 0.398 & 0.678 & 0.661 & 0.637 & 0.781 & 0.776 & 0.728 \\
DK1 & & & & & 1 & 0.865 & 0.290 & 0.294 & 0.277 & 0.348 & 0.339 & 0.305 \\
DK2 & & & & & & 1 & 0.353 & 0.346 & 0.334 & 0.422 & 0.414 & 0.341 \\
NO1 & & & & & & & 1 & 0.979 & 0.963 & 0.888 & 0.894 & 0.566 \\
NO2 & & & & & & & & 1 & 0.959 & 0.867 & 0.873 & 0.575 \\
NO3 & & & & & & & & & 1 & 0.853 & 0.858 & 0.543 \\
NO4 & & & & & & & & & & 1 & 0.988 & 0.624 \\
NO5 & & & & & & & & & & & 1 & 0.626 \\
EE & & & & & & & & & & & & 1 \\
\hline
\end{tabular}

Column (1) of table 6 shows the estimation results of the SDM when using the transmission weight matrix. The estimated coefficient on the spatially lagged dependent variable $W p_{t}$ is significant and expresses strong spatial dependence. This result indicates some important implications in spot price modeling. From a spot price modeling perspective it shows that current spot prices in other markets are important variables in determining current spot prices of a particular bidding market. Thus, joint modeling of space-time effects in spot prices can help improve forecasts. From an econometrics point of view, appropriate consideration of the spatial lag variables can help avoid omitted variable bias problem. The difference found in the coefficient estimates of $p_{t-1}$, for example, in table (4) and (6) might reflect the size of omitted variable bias problem.

The estimation results of the SDM when using floating weight matrix are shown in column (3) of table 6. As shown in the table the estimation results produce more or less similar results in column (1). The spatially lagged current spot price has a significant positive coefficient estimate. Similar results are obtained when using a contiguity weight matrix, see column (2) in table 6 .

These results support the hypothesis that a spot price observed at a particular market is determined by what happens elsewhere in the system. This is intuitive since highly interconnected transmission systems, temporal demand and supply imbalances, price competition and transmission congestion in electricity spot prices may result in spatial price dependence between markets. Unobserved features such as generating production capacity and maintenance problems are also likely to result in spot price spatial dependence. 
Table 6: Estimation results of the SDM

\begin{tabular}{lccc}
\hline \hline Model & Transmission $W$ & Contiguity $W$ & Float $W$ \\
\hline & & & \\
Constant & $0.661[0.218]^{* * *}$ & $0.434[0.091]^{* * *}$ & $0.422[0.129]^{* * *}$ \\
$p_{t-1}$ & $0.379[0.053]^{* * *}$ & $0.409[0.065]^{* * *}$ & $0.391[0.059]^{* * *}$ \\
$p_{t-2}$ & $0.159[0.009]^{* * *}$ & $0.158[0.0213]^{* * *}$ & $0.169[0.013]^{* * *}$ \\
$p_{t-3}$ & $0.057[0.016]^{* * *}$ & $0.121[0.019]^{* * *}$ & $0.069[0.014]^{* * *}$ \\
$p_{t-4}$ & $0.124[0.010]^{* * *}$ & $0.125[0.012]^{* * *}$ & $0.138[0.008]^{* * *}$ \\
$H D D$ & $0.0001[0.001]$ & $-0.0001[0.000]$ & $-0.00008[0.001]$ \\
$C D D$ & $0.0013[0.002]$ & $-0.0004[0.001]$ & $0.002[0.002]$ \\
Mon & $0.006[0.009]$ & $0.008[0.009]$ & $0.007[0.010]$ \\
Tue & $0.069[0.029]^{* *}$ & $0.051[0.016]^{* *}$ & $0.046[0.023]^{* *}$ \\
Wed & $0.029[0.016]^{* *}$ & $0.028[0.011]^{*}$ & $0.021[0.013]$ \\
Thu & $0.044[0.025]^{* *}$ & $0.031[0.012]^{* * *}$ & $0.028[0.021]$ \\
Fri & $0.036[0.022]^{* *}$ & $0.025[0.009]^{* *}$ & $0.022[0.018]$ \\
Sat & $0.029[0.017]^{* *}$ & $0.021[0.010]^{* *}$ & $0.019[0.014]$ \\
\hline$W * p_{t}(\rho)$ & $0.643[0.074]^{* * *}$ & $0.765[0.035]^{* * *}$ & $0.773[0.029]^{* * *}$ \\
$W * p_{t-1}$ & $-0.269[0.051]^{* * *}$ & $-0.242[0.068]^{* * *}$ \\
$W * p_{t-2}$ & $-0.148[0.087]^{* *}$ & $-0.149[0.027]^{* * *}$ & $-0.174[0.019]^{* * *}$ \\
$W * p_{t-3}$ & $-0.164[0.011]^{* * *}$ & $-0.128[0.026]^{* * *}$ & $-0.073[0.014]^{* * *}$ \\
$W * p_{t-4}$ & $-0.116[0.013]^{* * *}$ & $-0.132[0.015]^{* * *}$ \\
$W * H D D$ & $-0.064[0.013]^{* * *}$ & $0.0003[0.0001]^{* *}$ & $0.0003[0.001]$ \\
$W * C D D$ & $-0.111[0.017]^{* * *}$ & $0.0003[0.001]$ & $-0.002[0.001]^{* *}$ \\
Wald test spatial lag & $0.0002[.001]$ & $52.97[0.000]^{* * *}$ & $335.07[0.000]^{* * *}$ \\
Wald test spatial error & $522.07\left[0.002[0.000]^{* * *}\right.$ & $129.06[0.000]^{* * *}$ & $253.46[0.000]^{* * *}$ \\
$R^{2}$ & 0.583 & 0.583 & 0.585 \\
\hline
\end{tabular}

Notes: $* * *(* *, *)$ denotes significance at $1 \%(5 \%, 10 \%)$ level. Standard errors are in parenthesis

for estimation results and p-values for Wald tests.

One can perform a Wald test to examine if the SDM reduces to either the spatial lag or spatial error model. The Wald test of restrictions on the SDM are reported in the lower panel of table 6. Accordingly, the hypothesis of the SDM can be simplified to either the spatial lag or spatial error model is rejected by the Wald test, respectively, (76.67, $\mathrm{p}=0.00)$ and $(522.09, \mathrm{p}=0.00)$ given that the transmission weight matrix is used. A similar conclusion holds under the contiguity and float weight matrices.

\subsection{Direct and Indirect effects}

The spatial spot price model in (3) provides very rich own and cross-partial derivatives that quantify the magnitude of direct and indirect or spatial spillover effects which arise from changes in bidding area $i$ 's characteristics such as weather conditions and previous spot prices, for instance. A change in a single observation of an explanatory variable will affect the bidding area spot price itself (the direct effect) and potentially affect all other bidding areas indirectly (the indirect effect/spatial spillover effects). The direct and indirect effects are the logical consequence of the SDM, since the model takes into account other bidding markets dependent and independent variables through the introduction of the spatially lagged dependent and spatially lagged independent variables. In fact, LeSage and Pace (2009) note that the ability of spatial regression models to capture these interactions represents an important aspect of spatial econometric models.

Taking the SDM in (3) as a point of departure, it can be rewritten as

$$
p_{t}=(I-\rho W)^{-1}\left(\beta p_{t-1}+\gamma W p_{t-1}+\theta_{1} Z_{t}+\theta_{2} W Z_{t}+\varepsilon_{t}\right)
$$


The $N x N$ matrix of partial derivatives of the spot price $p_{t}$ with respect to an explanatory variable, $p_{t-1}$, for example, for all spatial units $i=1, \ldots, N$ is

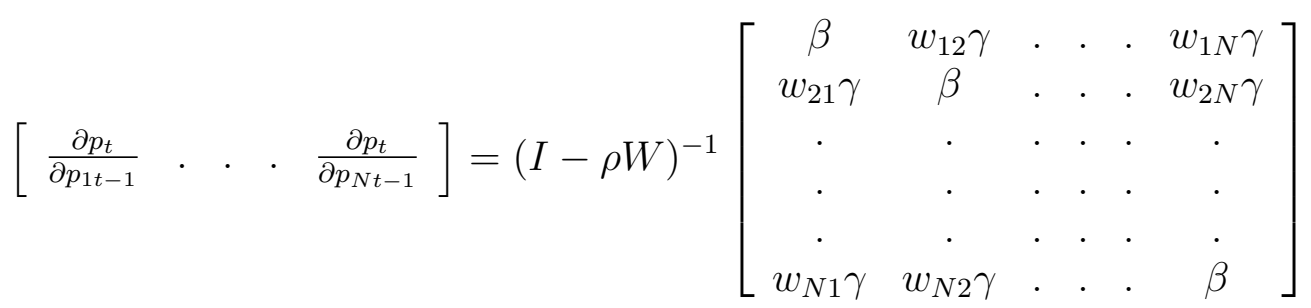

where $w_{i j}$ is the $(i, j)^{t h}$ element of the weight matrix $W$. The direct effect is measured by the average of the diagonal elements while the indirect (or spatial) spillover effect is measured by the average of either the row or column sums of the non-diagonal elements. However, the numerical magnitudes of the row and column sums of the indirect effects are the same implying that it does not matter which one is used (LeSage and Pace 2009 and Elhorst 2010). A general SDM model with $k$ explanatory variables, leads to $k x N^{2}$ partial derivatives. See Elhorst (2010) for a detailed illustration of direct and indirect effects decomposition.

Table 7 reports the direct, indirect and total effects estimation results of the spatial Durbin spot price model. Because the direct and indirect effects are composed of different coefficient estimates, LeSage and Pace (2009) suggest simulating the distribution of the direct and indirect effects using the variance-covariance matrix implied by the maximum likelihood estimates in order to draw inferences about the statistical significance of the direct and indirect effects.

To conserve space, we do not report the coefficient estimates of the dummy variables. Since the direct and indirect effects results are similar when using transmission, contiguity and float weight matrices, only the results for transmission weight matrix are reported. As shown in the table, both the direct and indirect effects of the first temporal lag coefficient are significant. The significant negative indirect effect shows that nearby prices spillover to closer bidding market regions.

Table 7: Effects decomposition of spot price dynamics

\begin{tabular}{lccc}
\hline \hline Model & Direct effect & Indirect effect & Total effect \\
\hline$p_{t-1}$ & $0.408[0.008]^{* * *}$ & $0.235[0.018]^{* * *}$ & $0.643[0.019]^{* * *}$ \\
$p_{t-2}$ & $0.142[0.011]^{* * *}$ & $-0.149[0.021]^{* * *}$ & $-0.008[0.023]$ \\
$p_{t-3}$ & $0.048[0.010]^{* * *}$ & $-0.075[0.025]^{* * *}$ & $-0.027[0.029]$ \\
$p_{t-4}$ & $0.115[0.009]^{* * *}$ & $-0.075[0.019]^{* * *}$ & $0.039[0.021]^{*}$ \\
$H D D$ & $0.0005[0.0003]^{* *}$ & $0.0007[0.0003]^{* *}$ & $0.0012[0.0006]^{* *}$ \\
$C D D$ & $0.0008[0.001]$ & $0.001[0.002]$ & $0.002[0.003]$ \\
$W * p_{t}(\rho)$ & $0.643[0.006]^{* * *}$ & 12662 \\
No. Obs. & \multicolumn{3}{c}{$369.29[0.000]^{* * *}$} \\
Wald test spatial lag & \multicolumn{3}{c}{$1183.89[0.000]^{* * *}$} \\
Wald test spatial error & \multicolumn{3}{c}{ Notes: ${ }^{* * *}\left({ }^{* *}{ }^{*}\right)$ denotes significance at $1 \%(5 \%, 10 \%)$ level. Standard errors are in parenthesis for model } \\
results and p-values are in parenthesis for Wald test results. Transmission weight matrix is used in the \\
direct anb indirect effects estimation.
\end{tabular}

\subsection{A time-varying coefficients SDM}

The Nordic power grid and the associated power market has experienced significant deregulation over the past 15 years. This concerns both the design of the auction market conditions and 
improvements in the physical power transmission system. The purpose of such deregulation and liberalization has been to improve the general competitive market environment for power. Intuitively, such deregulation should increase spatial price correlation across power grid points and hence considering the spatial correlation fixed for a long sample period is questionable.

In this section, we estimate our SDM using recursive estimation to examine the evolution of the coefficient estimates of the spot price SDM over time and with particular focus on the spatial correlation. To this end, we use a somewhat longer time series for spot prices data that covers the period 1 January 2000 to 18 October 2014. Because longer time series observations of data are not available for all 13 bidding markets, we consider only 9 bidding markets for which we have daily spot price data covering the entire sample period. We use one bidding market in Sweden, five bidding markets in Norway, the two bidding markets in Denmark and one bidding market in Finland. We employ 2 months rolling window recursive estimation of the SDM.

The evolution of time varying coefficient of the spatially lagged dependent variable implied by the spatial Durbin model is displayed in figure 4 . The recursive estimates of the spatial correlation coefficient are shown (red line), together with $95 \%$ confidence bands (blue lines).

Figure 4: Time varying spatial correlation coefficient

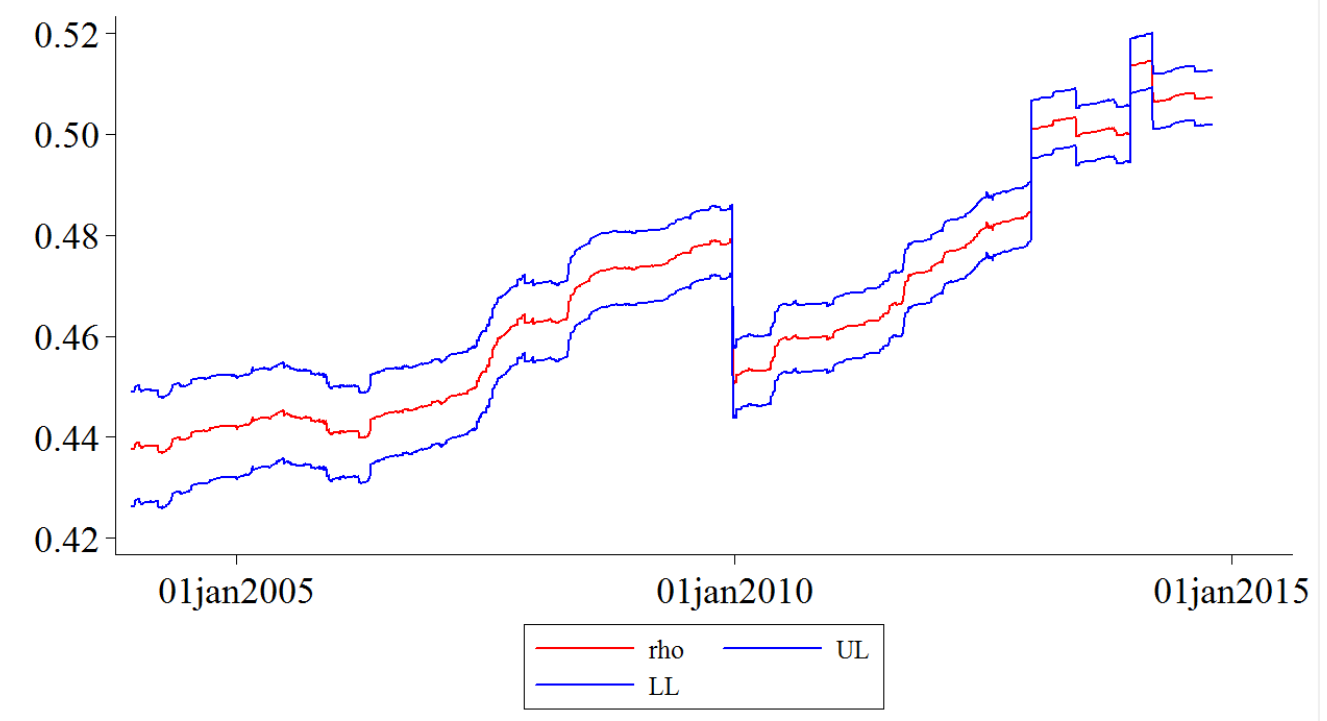

As seen the spatial correlation exhibits certain jumps in the sample period, particularly in January 2010. These jumps are caused by extreme price spikes in the Nordic power area that consequently were scrutinized by the regulatory authorities, see e.g. NordReg (2011). The jumps are caused by circumstances that can be considered unusual and hence can be expected to result in instability of the empirical estimates. Notwithstanding, it is very obvious that over the sample period considered, there has been an increasing trend in the spatial correlation within the Nord Pool grid. We interpret this empirical finding as rather strong evidence of increased market integration and competition across the bidding areas. 


\section{Conclusion}

Spatial panel econometric models are becoming important to describe many observed economic processes. We use tools from spatial econometrics to examine the spatio temporal patterns of electricity spot prices within the Nord Pool power grid. A spatial Durbin model that incorporates space-time effects in the dynamics of electricity spot prices is developed.

Our general spatial Durbin model enables analysis of the dynamics of electricity spot prices both across regions and over time. Because the spatial Durbin model nests spatial error and spatial lag models as a special case, it produces unbiased coefficient estimates, also if the true model is a spatial lag or spatial error model.

Different spatial weight matrices such as weight matrix constructed from transmission capacities, geographical contiguity weight matrix and float weight matrix are considered to capture the structure of the spatial interaction among different Nord Pool electricity spot price regions. Different statistical tests show that the non spatial spot price model is rejected in favor of a space-time effects model.

Estimation of the spatial Durbin model shows that the spatial dimension plays a significant role in describing electricity spot price dynamics. This is particularly important when prices and loads are determined in a network grid of power exchange regions.

For a dynamic spatial Durbin model, a change in the explanatory variable (e.g., previous period spot prices) of a particular region not only affects the current spot price of that particular region (the direct effect) but also the current spot prices in other regions (the indirect effects). Using LeSage and Pace's (2009) partial derivatives approach, we decompose the price impacts into direct and indirect effects and we show that price effects transmit to neighboring markets and decline with distance

In order to examine the evolution of the spatial correlation coefficient over time, we estimate a time varying spot price spatial Durbin model. We find that the spatial price correlation coefficient within the Nord Pool grid has been increasing remarkably over time which we interpret as a measure of increasing degree of market integration for the sample period considered.

This paper opens up for some future research directions in electricity price modeling and forecasting. It is obvious from the empirical findings of the current paper that spatial effects are extremely important in describing the electricity price dynamics. However, when moving on to analyze high frequency hourly electricity price data (rather than daily average prices), the possibility of congestion and non-congestion episodes across regions becomes important. The building of empirical models that can capture such (spatial) regime switching price behavior is a challenging modeling task that can contribute further to better understand the complex spatio-temporal dynamics of power prices.

\section{References}

[1] Anselin, L. (1988). Spatial Econometrics: Methods and Models. Kluwer Academic Publishers.

[2] Anselin, L., A. K. Bera, R. Florax, and M. J. Yoon (1996). Simple diagnostic tests for spatial dependence. Regional Science and Urban Economics 26: 77-104.

[3] Case, A. (1991). Spatial Patterns in Household Demands. Econometrica 4:593-965. 
[4] Case, A.C., Rosen, H.S. and Hines, J. R. (1993). Budget Spillovers and Fiscal Policy Interdependence. Journal of Public Economics 52: 285-307.

[5] Conley, T.G. \& G. Topa., (2002). Socio-economic Distance and Spatial Patterns in Unemployment. Journal of Applied Econometrics 17: 303-327.

[6] Deng, S.J., (1999). Stochastic models of energy commodity prices and their applications: mean-reversion with jumps and spikes. Working Paper. University of California at Berkeley, Berkeley, California.

[7] Douglas, S. and Popova, J. (2011). Econometric Estimation of Spatial Patterns in Electricity Prices.The Energy Journal 81-106.

[8] Efimova, O. and Serletis, A. (2014). Energy markets volatility modeling using GARCH. Energy Economics 43: 264-273.

[9] Elhorst, P. (2010) Applied spatial econometrics: raising the bar. Spatial Economic Analysis 5:9-28.

[10] Elhorst, P. (2012) Dynamic Spatial Panels: Models, Methods and Inferences. Journal of Geographical Systems 14: 5-28.

[11] Elhorst, P. and Yesilyurt, F. (2014). A regional analysis of inflation dynamics in Turkey. Annals of Regional Science, 52: 1-17.

[12] Ertur, C. and Koch, W. (2007). Growth, Technological Interdependence and Spatial Externalities: Theory and Evidence. Journal of Applied Econometrics 22: 1033-1062.

[13] Fernandez, V. 2011. Spatial linkages in international financial markets. Quantitative Finance 11: 237-245.

[14] Giacomini, R. and Granger, C. (2004). Aggregation of space-time processes. Journal of Econometrics 118: 7-26.

[15] Hadsell, L. Marathe, A. and Shawky, H. (2004). Estimating the volatility of wholesale electricity spot prices in the US. The Energy Journal 25: 23-40.

[16] Haldrup, N., Nielsen, Frank, S. and Nielsen M.Ø. (2010). A vector autoregressive model for electricity prices subject to long memory and regime switching. Energy Economics 32: 1044-1058

[17] Haldrup, N. and Nielsen M.Ø. (2006). A rigime Switching long memory model for electricty prices. Journal of Econometrics 135: 349-376.

[18] Huisman, R., Mahieu, R. (2003). Regime jumps in electricity prices. Energy Economics 25: $425-434$.

[19] Kelejian, H.H. and I.R. Prucha (1999). A Generalized Moments Estimator for the Autoregressive Parameter in a Spatial Model. International Economic Review 40: 509-533.

[20] Lee, LF (2010). Asymptotic Distributions of Quasi-Maximum Likelihood Estimators for Spatial Autoregressive Models. Econometrica 72:1899-1925. 
[21] Lee, LF and Yu, J. (2008). Estimation of spatial autoregressive panel data models with fixed effects. Journal of Econometrics 154:165185.

[22] Leenders, R. (2002). Modeling social influence through network autocorrelation: constructing the weight matrix. Social Networks 24:21-47.

[23] LeSage, J. (1997). Regression Analysis of Spatial Data. The Journal of Regional Analysis and Policy 27: 83-94.

[24] LeSage, J. and Fischer, M. (2008). Spatial Growth Regressions: Model Specification, Estimation and Interpretation. Spatial Economic Analysis, Taylor and Francis Journals 3: 275-304.

[25] LeSage, J. and Pace, R. (2009). Introduction to Spatial Econometrics, Boca Raton: Taylor and Francis.

[26] NordReg. (2011). NordREG report on the price peaks in the Nordic wholesale market during winter 2009-2010, Report 1/2011.

[27] Nord Pool. (2004). The Nordic power market, electricity power exchange across national borders. www.nordpool.no

[28] Nord Pool. (2013). Nordic Market report 2013: Development in the Nordic Electricity Market Nordic Energy Regulators.

[29] Park, H., Mjelde, James W. and Bessler, D. (2006). Price dynamics among U.S. electricity spot markets. Energy Economics 28: 81-101. 


\section{Research Papers 2013}

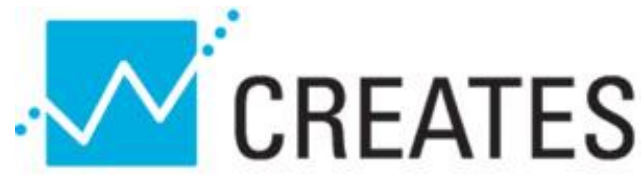

Center for Research in Econometric Analysis of Time Series

2015-05: Peter Christoffersen and Xuhui (Nick) Pan: Equity Portfolio Management Using Option Price Information

2015-06: Peter Christoffersen and Xuhui (Nick) Pan: Oil Volatility Risk and Expected Stock Returns

2015-07: $\quad$ Peter Christoffersen, Bruno Feunou and Yoontae Jeon: Option Valuation with Observable Volatility and Jump Dynamics

2015-08: $\quad$ Alfonso Irarrazabal and Juan Carlos Parra-Alvarez: Time-varying disaster risk models: An empirical assessment of the Rietz-Barro hypothesis

2015-09: Daniela Osterrieder, Daniel Ventosa-Santaulària and Eduardo Vera-Valdés: Unbalanced Regressions and the Predictive Equation

2015-10: $\quad$ Laurent Callot, Mehmet Caner, Anders Bredahl Kock and Juan Andres Riquelme: Sharp Threshold Detection Based on Sup-norm Error rates in Highdimensional Models

2015-11: $\quad$ Arianna Agosto, Giuseppe Cavaliere, Dennis Kristensen and Anders Rahbek: Modeling corporate defaults: Poisson autoregressions with exogenous covariates (PARX)

2015-12: $\quad$ Tommaso Proietti, Martyna Marczak and Gianluigi Mazzi: EuroMlnd-D: A Density Estimate of Monthly Gross Domestic Product for the Euro Area

2015-13: $\quad$ Michel van der Wel, Sait R. Ozturk and Dick van Dijk: Dynamic Factor Models for the Volatility Surface

2015-14: $\quad$ Tim Bollerslev, Andrew J. Patton and Rogier Quaedvlieg: Exploiting the Errors: A Simple Approach for Improved Volatility Forecasting

2015-15: Hossein Asgharian, Charlotte Christiansen and Ai Jun Hou: Effects of Macroeconomic Uncertainty upon the Stock and Bond Markets

2015-16: $\quad$ Markku Lanne, Mika Meitz and Pentti Saikkonen: Identification and estimation of non-Gaussian structural vector autoregressions

2015-17: $\quad$ Nicholas M. Kiefer and C. Erik Larson: Counting Processes for Retail Default Modeling

2015-18: $\quad$ Peter Reinhard Hansen: A Martingale Decomposition of Discrete Markov Chains

2015-19: $\quad$ Peter Reinhard Hansen, Guillaume Horel, Asger Lunde and Ilya Archakov: A Markov Chain Estimator of Multivariate Volatility from High Frequency Data

2015-20: Henri Nyberg and Harri Pönkä: International Sign Predictability of Stock Returns: The Role of the United States

2015-21: $\quad$ Ulrich Hounyo and Bezirgen Veliyev: Validity of Edgeworth expansions for realized volatility estimators

2015-22: $\quad$ Girum D. Abate and Niels Haldrup: Space-time modeling of electricity spot prices 